\title{
Outcomes of Total Parathyroidectomy with Autotransplantation versus Subtotal Parathyroidectomy Techniques for Secondary Hyperparathyroidism in Chronic Renal Failure
}

\author{
Ramazan Sari, Hakan Yabanoglu, Abdirahman Sakulen Hargura, Murat Kus and Ilker Murat Arer \\ Department of General Surgery, Baskent University, Adana Medical and Research Center, Adana, Turkey
}

\begin{abstract}
Objective: To compare the safety and the effectiveness of total parathyroidectomy with autotransplantation versus subtotal parathyroidectomy for refractory secondary hyperparathyroidism in patients with chronic kidney disease.

Study Design: A comparative study.

Place and Duration of Study: Baskent University, Adana Medical and Research Center, Adana, Turkey, from January 2012 to November 2018.

Methodology: Patients operated upon for refractory secondary hyperparathyroidism by the general surgery team were inducted. Overall, 25 (40\%) patients underwent total parathyroidectomy with autotransplantation (Group 1), whereas 37 (60\%) patients underwent subtotal parathyroidectomy (Group 2). Patient files were retrospectively analysed for recurrence or persistence of hyperparathyroidism.

Results: A total of 62 patients, $32(52 \%)$ of whom were females, with a mean age of $41.4 \pm 15.8$ years for group 1; and 30 patients were males with a mean age of $43.1 \pm 16.7$ years for group 2 were assessed in this study. The presenting complaints were bone pains and malaise supported by laboratory values that showed consistently elevated parathyroid hormone levels (>200 pg/ml). In the postoperative follow-up, 29 patients $(46.8 \%)$ had transient hypocalcemia, while $3(5 \%)$ had persistent hypoparathyroidism. In Group 1, one (4\%) patient had a recurrence, while $4(16 \%)$ patients had persistent hyperparathyroidism. In contrast, two (5.6\%) patients in Group 2 had recurrence, whereas $8(22 \%)$ patients had persistent hyperparathyroidism.

Conclusion: Both surgical options can be safely utilised in the management of refarctory secondary hyperparathyroidism. Moreover, regardless of the procedure used, all the parathyroid glands must be explored. However, due to high morbidity and failure rates of subsequent surgeries, the surgeon should be keen and thorough in the initial procedure.
\end{abstract}

Key Words: Chronic renal failure, Secondary hyperparathyroidism, Parathyroidectomy.

How to cite this article: Sari R, Yabanoglu H, Hargura AS, Kus M, Arer IM. Outcomes of total parathyroidectomy with autotransplantation versus subtotal parathyroidectomy techniques for secondary hyperparathyroidism in chronic kidney renal failure. J Coll Physicians Surg Pak 2020; 30(1):18-22.

\section{INTRODUCTION}

Secondary hyperparathyroidism (sHPT) is common in chronic kidney disease (CKD). It is characterised by markedly elevated parathyroid hormone levels due to persistent stimulation of parathyroid tissue and resultant parathyroid hyperplasia in response to hypocalcemia. ${ }^{1}$ The chronically elevated parathyroid hormone causes bone pain, general weakness, malaise, neuropsychiatric symptoms, and renal osteodystrophy. Secondary hyperparathyroidism has also been linked to cardiovascular mortality in patients with heart failure. ${ }^{2}$

To manage this condition, agents like phosphate binders, activated vitamin D (calcitriol), and calcimimetics are

Correspondence to: Dr. Ramazan Sari, Department of General Surgery, Baskent University, Adana Medical and Research

Center, Adana, Turkey

E-mail: sariramazan71@gmail.com

Received: July 08, 2019; Revised: October 24, 2019;

Accepted: November 25, 2019 generally used. ${ }^{3}$ Though medical management is adequate in mild to moderate cases, studies have shown that only $22 \%$ of severe cases respond to medical management. 4 Approximately $20 \%$ of sHPT patients with 3-10 year history of CKD require surgery; these rates are as high as $40 \%$ in patients with 20 years history of CKD. 5 After parathyroidectomy, parathyroid hormone levels drop rapidly to normal range resulting in reduced mortality and morbidity rates. 6

Surgically, the most commonly used procedures are subtotal parathyroidectomy (stPT), which is the removal of all parathyroid glands, save half of the most normallooking gland; and parathyroidectomy with auto-transplantation (tPTO), which is the removal of all the four glands and implantation of a section of one of the glands into a muscle. While stPT carries a lower risk of hypocalcemia and permanent hypoparathyroidism, tPTO reportedly has a lower risk of recurrence and needs subsequent re-exploration. ${ }^{7}$ 
There are studies that compare the two procedures in the set up of sHPT. This study differs to answer the question of the better procedure when a surgeon is faced with both options at a centre with a team that is dedicated to the management of these conditions.

The objective of this study was to compare the safety and the effectiveness of total parathyroidectomy with autotransplantation versus subtotal parathyroidectomy in terms of recurrence and persistence of refractory secondary hyperparathyroidism in patients with chronic kidney disease.

\section{METHODOLOGY}

Baskent University Medical and Health Sciences Research Board Ethics Committee approved this study (Project No. KA 19/175). Sixty-two CKD patients operated upon for secondary hyperparathyroidism refractory to medical management between January 2012 and November 2018 in Baskent University's Adana Hospital, were included in the study. Exclusion criteria comprised a history of a previous thyroid or parathyroid operation, re-operation because of technical inadequacy, and incomplete patient files. The files and data of the patients were retrospectively analysed. The patients were put into two groups: Group 1 for tPTO $(n=25)$ and Group 2 for stPT $(n=37)$. Demographic and clinical characteristics, preoperative laboratory results, preoperative ultrasound, parathyroid scintigraphy and surgical notes were recorded.

In both groups, all four glands were explored and the frozen section used to confirm the tissue as parathyroid. In Group 1, the most normal-appearing gland was immersed in physiologic serum at $+4^{\circ} \mathrm{C}$ and then subdivided into $1 \mathrm{~mm}^{3}$ pieces before being transplanted into the brachioradialis muscle in the forearm. In Group 2, approximately $50 \mathrm{mg}(1 / 2-1 / 3)$ of the most normalappearing gland was left in situ and marked with surgical clips. The patients were discharged on oral calcium and vitamin D. Patients with symptomatic hypocalcemia received IV calcium treatment. The hospitalisation duration and postoperative complications were noted. Laboratory values were analysed at one week, one month, and six months. Persistent hypoparathyroidism was defined as PTH levels above $200 \mathrm{pg} / \mathrm{ml}$ before six months, whereas recurrence was defined as PTH levels rising above $200 \mathrm{pg} / \mathrm{ml}$ after the six months.

Statistical analysis was performed using the statistical package SPSS (Version 23.0, SPSS Inc., Chicago, IL, USA). If continuous variables were normal, they were described as the mean \pm standard deviation ( $p>0.05$ in Kolmogorov-Smirnov test or Shapiro-Wilk $(n<30)$ ), but if the continuous variables were not normal, they were described as the median with IQR (interquartile range).
Comparisons between groups were applied using the Student t-test for normally distributed data, and the Mann-Whitney U-test was used for the data not normally distributed. The categorical variables between the groups were analysed using the Chi-square test or the Fisher exact test. Values of $p<0.05$ were considered statistically significant.

\section{RESULTS}

A total of 62 patients including 32 females [52\%] were inducted in this study. Their mean age was $41.4 \pm 15.8$ years for group 1 and $43.1 \pm 16.7$ years for group 2 . The presenting complaints were bone pain, malaise and laboratory studies that showed consistently elevated parathyroid hormone levels $(>200 \mathrm{pg} / \mathrm{ml})$. Demographic and clinical characteristics were similar in both groups. The mean preoperative laboratory results, preoperative parathyroid ultrasonography, and scintigraphic findings were recorded as given in Table I.

Four patients in group 1 and six in group 2 had simultaneous thyroidectomy. Four parathyroid glands were identified in $51(82 \%)$ patients. In $3(5 \%)$ patients, only 2 glands were identified during exploration. These patients subsequently developed persistent hyperparathyroidism. In $2(3 \%)$ patients, 5 parathyroid glands were identified. Ectopic glands identified in $5(8 \%)$ patients were mostly intrathymic.

Twenty-nine (46.8\%) patients developed hypocalcemia and $3(5 \%)$ patients developed permanent hypoparathyroidism, whereas $29(46.8 \%)$ patients had no compli-

Table I: The demographic details and perioperative values of the patients.

\begin{tabular}{l|c|c|c}
\hline & Group-1 (n:25) & Group-2 (n:37) & $\mathrm{P}$ \\
\hline Age (Mean \pm SD) & $41.4 \pm 15.8$ & $43.1 \pm 16.7$ & 0.572 \\
\hline Gender & $14(56 \%)$ & $16(43.2 \%)$ & 0.438 \\
Male & $11(44 \%)$ & $21(56.8 \%)$ & \\
Female & & & \\
\hline Comorbidity & $8(32 \%)$ & $9(24.3 \%)$ & 0.569 \\
Yes & $17(68 \%)$ & $28(75.7 \%)$ & \\
No & $11.1 \pm 5.1$ & $8.7 \pm 3.9$ & 0.054 \\
\hline CKD years (Mean \pm SD) & & & \\
\hline Presenting complaint & $13(52 \%)$ & $15(41 \%)$ & 0.669 \\
Bone pain & $12(48 \%)$ & $22(59 \%)$ & \\
Malaise & $9.39 \pm 1.49$ & $9.646 \pm 1.20$ & 0.463 \\
Ca (mg/dl) & $1612(691)$ & $1539(971)$ & 0.428 \\
Pth (pg/ml) & $6.25 \pm 1.59$ & $5.25 \pm 1.44$ & 0.015 \\
P (mg/dl) & $297(363)$ & $330(440)$ & 0.859 \\
Alp (u/l) & & & \\
USG finding & $24(96 \%)$ & $30(81 \%)$ & 0.128 \\
Positive & $1(4 \%)$ & $7(19 \%)$ & \\
Negative & & $33(89 \%)$ & 0.640 \\
\hline Scintigraphy finding & $24(96 \%)$ & $4(11 \%)$ & \\
Positive & $1(4 \%)$ & & \\
Negative & &
\end{tabular}

${ }^{*} C K D$ : Chronic kidney disease.

Data are presented as mean \pm standard deviation or number (\%).

$p<0.05$ value is statistically significant. 
cations. The mean hospitalisation period was $5.1 \pm 4.1$ days, while follow-up was $38.7 \pm 22.9$ months. The postoperative follow-up data of the patients is shown in Table II.

Parathyroid hormone drop on postoperative day 1 was meaningful in group 1 compared to group 2, with a statistically significant difference $(p=0.03)$. But during follow-up serum $\mathrm{Ca}$, PTH levels on week 1 , 1st month and 6th month showed no statistically significant difference $(p>0.05)$. The mean values of these data are given in Figures $1 \mathrm{a}$ and $1 \mathrm{~b}$.

Table II: Postoperative follow-up data.

\begin{tabular}{l|c|c|c}
\hline & Group-1 (n:25) & Group-2 (n:37) & $\mathrm{p}$ \\
\hline Complication & $13(52 \%)$ & $16(43.2 \%)$ & 0.789 \\
$\begin{array}{l}\text { Transient hypocalcemia } \\
\text { Permanent hypocalcemia }\end{array}$ & $1(4 \%)$ & $2(5.4 \%)$ & \\
Myocardial Infarction & - & $1(2.7 \%)$ & \\
\hline Hospitalisation & $5(6)$ day & $3(5)$ day & 0.304 \\
\hline Follow-up time & $41(28)$ month & $37,5(36)$ month & 0.417 \\
\hline Recurrent HPT & $1(4 \%)$ & $2(5.6 \%)$ & 1 \\
Yes & $24(96 \%)$ & $35(94.6 \%)$ & \\
No & & & \\
\hline Persistent HPT & $4(16 \%)$ & $8(21.6 \%)$ & 0.745 \\
Yes & $21(84 \%)$ & $29(28.4 \%)$ & \\
No & & & \\
\hline
\end{tabular}

Data are presented as median (interquartile range) or number (\%). $p<0.05$ value is statistically significant.

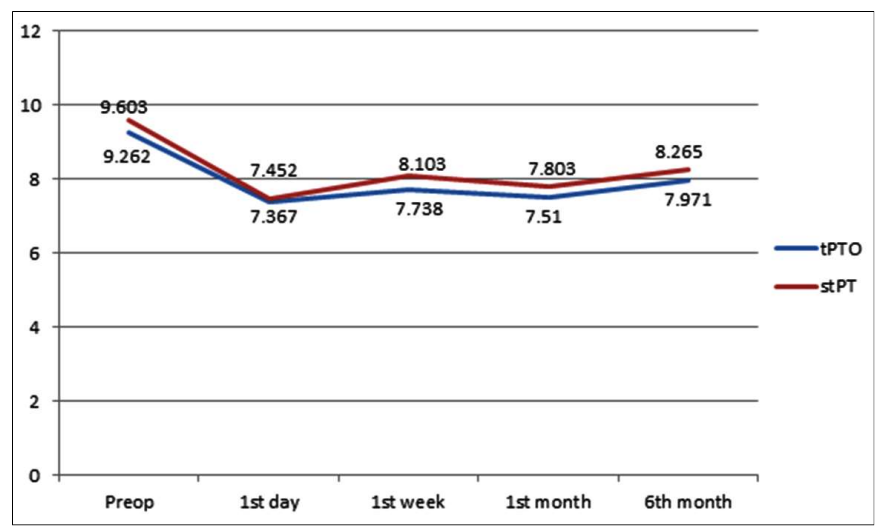

Figure 1 (a): Calcium level changes.

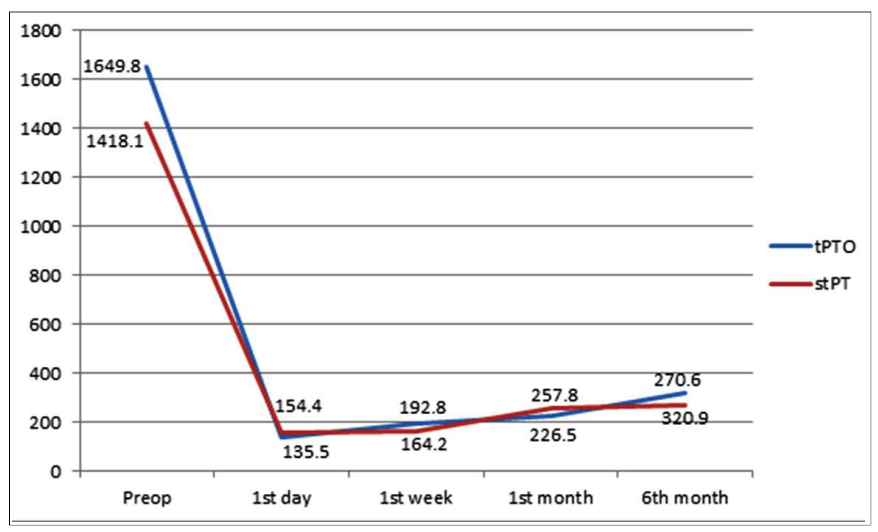

Figure 1 (b): Parathyroid hormone level changes

\section{DISCUSSION}

Secondary hyperparathyroidism is a CKD-related condition that compounds its morbidity and mortality. sHPT prevalence is almost $86 \%$ in end-stage renal disease. 8 Although vitamin $\mathrm{D}$ and calcimimetics are useful in medical management, these medications are not always effective and are expensive. 9 Therefore, $1-2 \%$ of sHPT patients require surgery every year. 10 There is a need for surgery when parathyroid hormone levels rise rapidly, and if there is extensive osteitis fibrosa cystica on imaging or rapid bone turnover that is refractory to medical treatment. ${ }^{11}$ The quality of life and symptoms have been shown to improve after parathyroidectomy.

Imaging techniques are not so highly sensitive and specific in diagnosing parathyroid hyperplasia,12 rendering localisation of these hyperplastic glands quite difficult and expensive. Thus, these localisation techniques should be preserved for persistent and recurrent cases. In this study, imaging was positive for hyperplasia, if at least one hyperplastic gland was identified on USG or if scintigraphy showed increased activity in at least one gland. This explains the positive findings in $87 \%$ of USG imaging and $92 \%$ of scintigraphic findings. The main strategy in surgery is to balance adequate parathyroid tissue resection and avoidance of permanent postoperative hypoparathyroidism. ${ }^{13}$ According to kidney disease outcomes and quality initiative (KDOQI) principles, the management should be based on patient's chances of renal transplantation such that patients on long-term dialysis should have their PTH levels maintained at $150-300 \mathrm{pg} / \mathrm{ml} .{ }^{14}$

The two main surgical management options are stPT and TPTO. Thymectomy should be added to routine bilateral cervical exploration so as no ectopic glands are overlooked. In tPTO, normal-looking gland is minced into $1 * 1 * 1 \mathrm{~mm}$ pieces and transplanted into sternocleidomastoid, brachioradialis or pectoralis muscles. ${ }^{15}$ In this study, brachioradialis muscle was preferred to avoid repeat neck exploration in case of persistence or recurrence and attain low morbidity in case of reoperation. StPT is associated with complications such as high recurrence rates, need for general anesthesia in case of re-operation and increased risk of recurrent laryngeal nerve injury during re-operation. 16 In contrast, tPTO carries a high risk of autograft failure resulting in permanent hypoparathyroidism. A systemic metaanalysis showed that both methods are effective in lowering serum PTH and calcium levels. One year follow-up revealed no recurrence as there was no detectable rise in PTH and calcium levels or an increase in the size of parathyroid tissue even in the subtotal parathyroidectomy group. ${ }^{17}$

In this study, first day PTH levels were significantly lower in the tPTO group $(p<0.05)$; but $6^{\text {th }}$ month PTH, $\mathrm{Ca}$, and 
$P$ levels showed no significant difference between the groups. Although there are studies that have shown a difference between the two methods, a meta-analysis of 13 studies looking at parameters such as clinical resolution, radiological improvement, recurrence, and persistent disease, found no statistically significant difference between the groups. 18 In this study, there was $1(4 \%)$ case of recurrence and $4(16 \%)$ cases of persistent disease in the tPTO group. In contrast, recurrence was seen in $2(5.6 \%)$ patients and persistent disease in $8(22 \%)$ patients in the stPT group. These figures seem to favour the tPTO group, but the study showed no statistically significant difference between the groups. Relatively, high persistent rates in this study can be attributed to inadequate exploration for ectopic glands as substantiated by recurrence or persistent disease in $8(89 \%)$ of 9 cases in which less than 4 glands were explored.

Total parathyroidectomy without autotransplantation (tPT) is another surgical technique used in sHPT management. A study comparing the three techniques found that there was no recurrence for the TPT group in a 3-year follow-up period. ${ }^{19}$ However, tPT is associated with debilitating clinical outcomes of permanent hypoparathyroidism.

The groups were also compared on complication rates and hospitalisation period. The calcium levels of the patients were checked daily, and if low, supplemented. Transient hypocalcemia was relatively high in both groups (52\% vs $43 \%)$, but with no statistically significant difference $(p>0.05)$. This difference in transient hypocalcemia may explain the longer hospitalisation period in the tPTO group (5.76 days vs. 4.65 days), but with no related statistical significance. Permanent hypoparathyroidism was $4 \%$ in tPTO and $5 \%$ in stPT with no statistically significant difference.

Because of increased morbidity and high failure rates associated with re-operation, the first operation should be done with the utmost dedication.

This study has limitations, such as its retrospective nature and lack of randomisation of surgical techniques. There are also variable recurrences and complication rates caused by the inexperience of a subgroup of surgeons at the Center of study. Determining the appropriate surgical technique for this subset of patients, will require a standardised randomised prospective study with a larger cohort.

\section{CONCLUSION}

Both surgical techniques are comparably effective in the treatment of hyperparathyroidism associated with CKD. Thymectomy should be added to the bilateral cervical exploration technique of choice to reduce the risk of recurrent or persistent disease due to ectopic hyperparathyroid gland.

\section{ETHICAL APPROVAL:}

This study was approved by Baskent University Institutional Review Board (Project No. KA 19/175) prior to initiation of the research work.

\section{PATIENTS' CONSENT:}

Informed consents were obtained from all patients to publish the data concerning this case.

\section{CONFLICT OF INTEREST:}

Authors declared no conflict of interest.

\section{AUTHORS' CONTRIBUTION:}

RS: Design of the work, authored the manuscript.

HY: Conception of idea and final approval.

ASH: Helped to draft the manuscript and interpretation.

MK: Data collection and analysis.

IMA: Data analysis and critical review of article.

\section{REFERENCES}

1. Slatopolsky E, Brown A, Dusso A. Pathogenesis of secondary hyperparathyroidism. Kidney Int Suppl 1999; 73:S14-9.

2. Khan AH, Rohra DK, Saghir SA, Udani SK, Wood R, Jabbar A. Response of a single 'mega intramuscular dose' of vitamin $D$ on serum 25OHD and parathyroid hormone levels. J Coll Physicians Surg Pak 2012; 22:207-12.

3. Bellorin-Font E, Ambrosoni P, Carlini RG, Carvalho AB, CorreaRotter R, Cueto-Manzano A, et al. Clinical practice guidelines for the prevention, diagnosis, evaluation and treatment of mineral and bone disorders in chronic kidney disease (CKDMBD) in adults. Nefrologia 2013; 33(Suppl 1):1-28.

4. Moe SM, Chertow GM, Coburn JW, Quarles LD, Goodman WG, Block GA, et al. Achieving NKF-K/DOQI bone metabolism and disease treatment goals with cinacalcet $\mathrm{HCl}$. Kidney Int 2005; 67:760-71.

5. Tominaga $\mathrm{Y}$, Uchida K, Haba T, Katayama A, Sato T, Hibi Y, et al. More than 1,000 cases of total parathyroidectomy with forearm autograft for renal hyperparathyroidism. Am J Kidney Dis 2001; 38:168-71.

6. Komaba H, Taniguchi $\mathrm{M}$, Wada A, Iseki $\mathrm{K}$, Tsubakihara $\mathrm{Y}$, Fukagawa M. Parathyroidectomy and survival among Japanese hemodialysis patients with secondary hyperparathyroidism. Kidney Int 2015; 88:350-9.

7. Albuquerque RFC, Carbonara CEM, Martin RCT, Dos Reis LM, do Nascimento CP Júnior, Arap SS, et al. Parathyroidectomy in patients with chronic kidney disease: Impacts of different techniques on the biochemical and clinical evolution of secondary hyperparathyroidism. Surgery 2018; 163:381-7.

8. Yang G, Zhang B, Zha XM, Wang NN, Xing CY. Total parathyroidectomy with autotransplantation for a rare disease derived from uremic secondary hyperparathyroidism, the uremic leontiasis ossea. Osteoporos Int 2014; 25:1115-21.

9. Drueke TB, Ritz E. Treatment of secondary hyperparathyroidism in CKD patients with cinacalcet and/or vitamin $D$ derivatives [Review]. Clin J Am Soc Nephrol 2009; 4:234-41.

10. Pitt SC, Sippel RC, Chen H. Secondary and tertiary hyperparathyroidism, state of the art surgical management. Surg Clin N Am 2009; 89:1227-39. 
11. Decker PA, Cohen EP, Doffek KM, Ashley BA, Bienemann ME, Zhu YR, et al. Subtotal parathyroidectomy in renal failure: Still needed after all these years. World J Surg 2001; 25:708-12.

12. Muros MA, Soto JB, Ruiz MJ, Portillo MR, Navarro AR, Guardia MB. Two-phase scintigraphy with technetium 99msestamibi in patients with hyperparathyroidism due to chronic renal failure. Am J Surg 2007; 193:438-442.

13. Lorenz K, Bartsch DK, Sancho JJ, Guigard S, Triponez F. Surgical management of secondary hyperparathyroidism in chronic kidney disease - a consensus report of the European Society of Endocrine Surgeons. Langenbecks Arch Surg 2015; 400:907-27.

14. Uhlig K, Berns JS, Kestenbaum B, Kumar R, Leonard MB, Martin KJ, et al. KDOQI US commentary on the 2009 KDIGO clinical practice guideline for the diagnosis, evaluation, and treatment of CKD-mineral and bone disorder (CKD-MBD). Am J Kidney Dis 2010; 55:773-99.

15. Santos RO, Ohe MN, Carvalho AB, Neves MC, Kunii I, Lazaretti-Castro $\mathrm{M}$, et al. Total parathyroidectomy with presternal intramuscular autotransplantation in renal patients: A prospective study of 66 patients. J Osteoporos 2012; 2012: 631243.

16. Patow CA, Norton JA, Brennan MF. Vocal cord paralysis and reoperative parathyroidectomy. A prospective study. Ann Surg 1986; 203:282-5.

17. Nichols P, Owen JP, Ellis HA, Farndon JR, Kelly PJ, Ward MK. Parathyroidectomy in chronic renal failure: A nine-year follow-up study. Q J Med 1990; 77:1175-93.

18. Chen J, Jia X, Kong X, Wang Z, Cui M, Xu D. Total parathyroidectomy with autotransplantation versus subtotal parathyroidectomy for renal hyperparathyroidism: A systematic review and meta-analysis. Nephrology (Carlton) 2017; 22:388-96.

19. Schlosser K, Bartsch DK, Diener MK, Seiler CM, Bruckner T, Nies $C$, et al. Total parathyroidectomy with routine thymectomy and autotransplantation versus total parathyroidectomy alone for secondary hyperparathyroidism: Results of a nonconfirmatory multicenter prospective randomized controlled pilot trial. Ann Surg 2016; 264:745-53. 